Alan I. Melzer is a professor of political economy and public policy at Cornegie Mellon University. An earlier version of this article was presented of the 1994 Konstanz Seminos in Insel Reichenas, Germany, and some material is indeded from earler work with Karl Brunner and Alex Cukserman. The author fhanks Dale Henderson and Bennetf McCallun for comments on earlier deafts.

\section{Information, Sticky Prices and Macroeconomic Foundations}

\section{Allan H. Meltzer}

秝紋 or decades, macroeconomists have listened to criticism from their professional colleagues about the absence of mictofoundations from most of what they say and do. A typical comment is: "I don't understand much about macroeconomics; how is it related to economics?" A possibly less-frivolous comment is that nothing can be said about macroeconomic policy until economists develop a macroeconomic theory from a microeconomic foundation. Anything less is branded "ad hoc" and dismissed.

Much of the work in macroeconomics of the past two decades has responded to these criticisms by attempting to build macroeconomics on an explicit micro-foundation. That is a wothwhile goal but it opens the question: Which foundation should that be? The current generation of academic researchers are as divided about the appropriate analytic model as their predecessors. Analytic paradigms now include multiple equilbrium, real business cycle, neoKeynesian, monetary-rational expectations, and eclectic models. Most have a microfoundation, but it is not the same foundation.

I do not question the presumption that a micro-foundation is useful. At issue is what the foundation should be. 1 question the relevance for monetary and macroeconomics of micro-loundations which feature a representative agent who trades on a complete set of Arrow-Debreu markets. Despite some limited successes, it is time to question whether this now widely accepted approach is likely to be fruitful and to suggest why I believe its stuccess will be limited. Success is relative, of course. Real business cycle theory has developed an explicit analysis of the transmission of productivity and terms of trade shocks. These shocks, though widely recognized earlier, had not been made the subject of an explicit model. NeomKeynesians and others have produced some suggestions about pricing. Overlapping-generations models of money, intertemporal substitution theories of unemployment, and productivity shock theories of the business cycle have not proved frutful. These models have not prom duced either an accepted foundation for macro theory or a verified theory of aggregate output, prices and interest rates. Perhaps they will in the future, but the results to date are not promising.

There are two main ways to tie micro and macro theories. The first is aggregation. Aggregation is an important and much neglected issue, but it is not my main theme Most current or recent research dispenses with the aggregation problem by assuming a representative individual. Here the old and new macroeconomics are equally deficient and open to charges of "arm waving" and "ad hocery." The representative individual is a useful working assumption for some purposes, but the representative individual discards an important difference between markets and individuals.

The second problem is the specific micro-foundation used for macro theory. Most of my discussion is directed there. I do not attempt to survey a large literature on micro theory, uncertainty and industrial organization. The implications of some of this literature for price stickiness is ably summarized in Gordon (1990). This paper is a personal statement, reflecting joint work as noted earlier.

The problem with existing micro-foundations that I emphasize is the neglect of costs of information. In Walrasian microfoundations, all trades take place at market clearing prices, and there is no cost of acquiring information. An auctioneer calls 
out the prices at zero cost and does not close transactions until all transactors are at an equilibrium. There is a numeraire, but there is no way for money to disturb the real value of production or purchases. Non-neutrality cannot arise. Attempts to graft a monetary disturbance onto these micro-foundations seem misdirected.

The hypothesis that all observed prices are market clearing prices does not imply that all individuals, behaving rationally, know those prices and fully adjust to them. Information is costly to acquire; time and resources must be used to collect, process and interpret-the latter especially-new data. Even in markets dominated by price takers, there are differences between the information processed and known to arbitragers and specialists and what is known to non-specialists. The representative individ ual paradigm ignores this distinction.

One way to proceed is by aggregating heterogenous individuals who face different costs of acquiring information, and much new work has taken this path. As Gordon (1990) emphasizes, at any time there are many different layers of pricing and output included in aggregate prices and output--suppliers, suppliers of suppliers, foreign producers, and so on. Instead of trying to aggregate over these many, diverse and changing levels of decisions, it may prove more useful to treat them as part of a stochastic process.

One of the problems with the hypothesis that "sticky" prices reflect decisions at different levels of aggregation comes out clearly in Gordon's paper. He argues that sluggish price adjustment reflects marginal cost pricing. "[Agents] care about the relation of their own price to their own costs, not to aggregate nominal demand. Unless a single agent believes that the actions of all other agents will make its marginal costs mimic the behavior of nominal demand with minimal lags, the aggregate price level cannot mimic nominal demand, and Keynesian output fluctuations result."

This argument has a perverse implication. Farmers or farms that operate in commodity markets with many competitors should be slowest to adjust to aggregate demand shocks. Yet commodity prices typically adjust quickly. Large industrial firmsGeneral Motors, Mitsubishi-know that they are a relatively large part of the economy, so they should adjust to aggregate demand more promptly than commodity producers. Typically, they do not.

Missing from Gordon's analysis is the difference in information and in costs of acquiring information. Commodities are traded on open markets, so prices promptly reflect changes in the factors affecting demand and supply. Prices of autos, steel, heavy industrial products and consumer durables are not set in organized markets. Information on which to base prices is more uncertain.

As Keynes recognized, a principal missing element is uncertainty about the future. Uncertainty and its twin, costs of information, make it rational for some firms to adjust prices slowly. Prices may be "sticky," as economists have observed for about as long as there has been a discipline.

Some economists will scoff that sticky prices are irrational or equivalent to leaving five, 50 or 500 dollar bills in the street. This is an error arising from dependence on Walrasian foundations and neglect of information costs. Yet, there is nothing novel about invoking costs of acquiring information to explain sluggish price adjustment or sticky prices. The positive slope of Lucas' (1972) aggregate supply curve arises from confusion between relative and absolute price changes; prices in that model do not immediately adjust to new information. The cost of learning whether a change in demand is an aggregate or relative change is infinite for one period and zero thereafter. In the neo-Keynesian models discussed in Ball and Mankiw (1994), costs of price adjustmentso-called menu costs-and "real rigidities" are assumed to be present. The authors accept that one of the principal costs of price adjustment is the cost of acquiring information relevant for a decision about how much to change price.

Given this widespread acceptance of information or transaction costs, what remains to be done? Lucas" (1972) model implies more rapid adjustment of prices and output to new information than we observe 
in practice. Could it be rational to adjust more slowly than in one week or month? Is the compelling fact that data on the price level are released monthly? Or is this information subject to error so that it takes longer to disseminate, interpret and act on these data? Neo-Keynesian models build on the model of an imperfectly competitive firm, with strong implications for profits and excess capacity that do not find empirical support at the micro level. If monopolistic elements and menu costs are the soutce of sticky prices, there are testable implications for the profits of different types of firms; there is a significant problem of reconciling continuous excess capacity with rational behavior. Further, as Gordon (1990) has noted, costs of adjusting output are neglected in these models. Yet these costs may be larger for many firms than costs of price adjustment. My principal criticism of both neoclassical and neo-Keynesian approaches is that they seek to explain why firms delay using available information. By putting the issue in that framework, they neglect the uncertainty that surrounds much of the aggregate and disaggregated data. This paper uses several strands of earlier work to explain rational price setting and gradual adjustment as a response to uncertainty about what current information implies. Information is costly to acquire and to interpret as in Brunner and Meltzer (1971) or Alchian (1977). As in Bomhoff (1983), a principal difficulty in interpreting information is uncertainty about how long changes will persist. This is the central idea developed in Brunner, Cukierman and Meltzer (1983), but we took the idea from Muth's (1961) seminal paper on rational expectations. In Meltzer (1982), I used these ideas to discuss price setting.

There are three separable aspects of pricing to consider. First, (some) prices are set by firms. Second, firms choose nominal values; they do not index or set a relative price. Third, prices that are set change less frequently than prices in auction markets.

Each aspect is important for macroeconomics. If some prices were not fixed in nominal value for at least one period, relative prices would be invariant to a monetary change. Delays in recognizing permanent changes in money or its growth rate would affect only real balances. At best, we would be forced to fall back on the real balance effect in consumption to explain short-term real effects of changes in money. A rational reason for setting some, but not all, nominal prices permits a more direct effect through inventory adjustment. Firms that hold inventories can both anticipate future price changes and buffer current transitory price changes by varying inventories. Because some prices are determined in auction markets, price setting introduces different speeds of adjustment and relative price changes. My extensive work with Brunner emphasized the relative prices of assets and output. This introduces the difference between the replacement cost, or the cost of current production, and the market price of existing assets. Asset prices adjust more rapidly than output prices particularly for assets that trade in organized markets. Hence, information costs (and transaction costs) are implicit in that framework as an explanation of changes in relative prices. My emphasis here is on information as in Brunner, Cukierman and Meltzer (1983). Relative price changes in response to nominal shocks are part of that story, but they remain in the background.

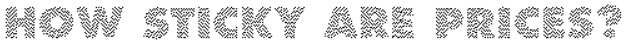

Postwar recessions typically last about nine months on average. Costs of information or other explanations of sluggish adjustment must be able to explain this timing, and estimates of price stickiness should be consistent with data on cyclical fluctuations. I digress therefore to consider a recent attempt to measure stickiness. Blinder (1991) reports preliminary findings from a survey of pricing decisions by managers of a random sample of corporations with annual sales of $\$ 10$ million located in the northeastern United States. Blinder's survey produced two very different sets of estimates.

First, Blinder reports the answer to a question about how frequently a firm changes its price. He finds that the median firm changes price about once a year. Nearly 
40 percent of the firms were at the median. More than one-sixth of the firms changed prices less freqtently than once a year, so 55 percent of the prices change no more than once a year.

Second, Blinder also teports the tespondents' estimate of the mean lag of actual prices behind increases and decreases in demand and cost. There is considerable uniformity in these responses. The mean lag for increases or decreases in demand and cost is three to four months.

The second set of data suggest considerable uniformity of response to the four shocks. There is little evidence of the asymmetric adjustment associated with Keynesian downward price inflexibility. The data also suggest an inconsistency that Blinder does not mention. How do we reconcile a mean delay of three to four months in response to changes in demand and cost with the report that 76 percent of the sample changes price no more than twice a year and, as noted, 55 percent changes price no more than once a year? Are demand and cost changes infrequent? It is difficult to reconcile the assumption that costs change infrequently with evidence showing that commodity prices and other open market prices change daily and typically fall in recessions and rise in expansions.

Blinder did not ask whether firms adjust their prices fully in response to changes in demand and cost. They may adjust partially, as implied by rational behavior under uncertainty about the persistence or permanence of announced changes, or they may anticipate future changes and adjust prices more than current changes in cost or demand. One way to reconcile the different responses is to assume that respondents answer the two questions in different ways. Suppose they treat price as a scalar when asked about the frequency of price changes but include in price adjustment more than just price setting. On this interpretation, quoted prices are one

Beaulieu mand Mattey \{1994\}

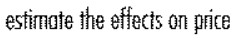
dispersion a factoss such or atwefising, tanspot costs, and concentuntion using cross-section dente for sperific contmotities. Thay ind elfects of some of these eloments on mice dispersion. component of a vector of terms and conditions relevant to sellers and buyers. The theoretical term price used in economics typically subsumes delivery time, discounts, advertising allowances, volume rebates, payment terms and other conditions used to adjust the buyer's cost and the seller's net receipts. Blinder's early results confirm that delivery lags and service are moderately important for 65 percent of the firms in his sample; he reports delivery lags and service are the most commonly cited reason for price stickiness. ${ }^{1}$ Delivery lags and service are one way of adjusting the theoretical term "price" while leaving the quoted price unchanged.

Assume that firms initially respond to changes in cost and demand by adjusting deliveries, advertising allowances, discounts, and so on while leaving quoted prices unchanged for several months or longer. If managers are uncertain about the duration of changes in demand or cost, they can change other components of the price vector to test the market's response. By changing delivery terms, or offering or removing discounts, firms can change their revenues or the buyers cost without changing the quoted price. This pricing model can be used to rationalize the familiar Keynesian supply curve - a reverse L-when quoted prices are distinguished from other terms in the price vector. Equally, the model can explain the difference in response to the questions in Blinder's survey.

Figure 1 shows the initial response to an increase in demand. Ot the left, the quoted price $(\rho)$ does not respond to a perceived change in demand when output is below capacity; the firm (or industry) increases output $(q)$ with little or no change in quoted price. On the right, the price vector $(p)$, includes other dimensions of the firm's price; supply is drawn as a positively sloped linear function. An increase in perceived demand from $d_{0}$ to $d_{1}$ induces the firm to reduce advertising allowances, remove discounts, or change some other component of the price vector, so $(p)$ increases.

If the firm's initial response reflects uncertainty about the persistence of increased demand, the response changes as information accrues. An increase in the quoted price may substitute for or supplement other components of the price vector. As perception of the magnitude of the permanent increase becomes clearer, the firm may recognize that the new demand curve is at, or to the right of, $d_{1}$. Or the firm may raise $\rho$, with $p$ unchanged. 
We need not explore the many possibilities. The main point is that uncertainty about the degree of persistence and the use of a price vector permit this hypothesis to account for very different responses within a rational expectations framework. In particular, the firm's revenues may respond instantly to increases in demand, but quoted prices may adjust with a long lag, as Blinder found. The teasoning is symmetric. Perceived reductions in demand may induce firms to offer discounts and allowances with $\rho$ unchanged. As information accrues and perceptions change, the actual price, $\rho$, is reduced.

The Keynesian supply function does not work for changes in cost if the demand curve is not kinked. Changes in cost shift the supply curve, so prices change instantly, whether the supply has a reverse L-shape or is monotonically increasing. Since Blinder's survey finds that price responds about as promptly to changes in cost as to changes in demand, this evidence rejects the Keynesian supply curve. ${ }^{2}$

The distinction between price as a vector and a scalar does not reconcile the differences in timing reported in the survey. Although 1 believe that prices, terms and conditions change at different rates when there is uncertainty about the persistence of the market conditions inducing frrms to change prices, those differences are neglected hereafter. Price stickiness will mean that it takes about three or four months on average for prices to respond to demand and cost changes. The three-to-four month delay that Blinder reports includes at least one quarterly reporting period at which managements announce earnings and sales and, most importantly, observe reported earnings, inventories and sales of competing firms. ${ }^{3}$ Knowledge of competitors' results helps the firm to supplement trade gossip and other informal data sources to decide whether a persistent change in market demand (or industry costs) has occurred.

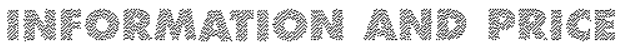

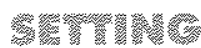

Anyone familiar with literature on the behavior of firms knows that there are many rational reasons for firms to set prices. This
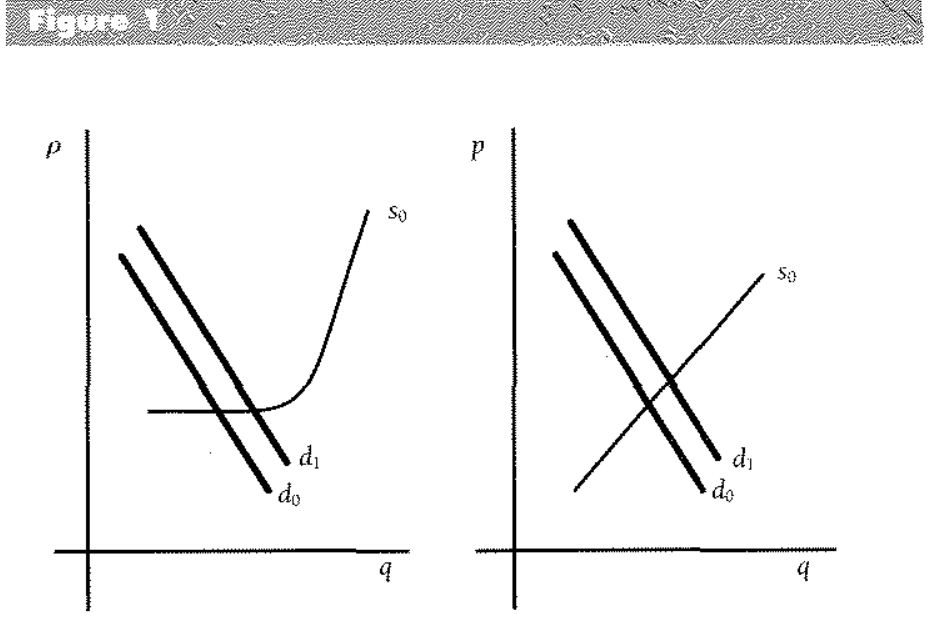

section discusses one reason that is rather general and can be incorpotated readily into macroeconomics. Price setting is considered as a response to uncertainty or costs of acquiring information about the market clearing price by at least one (large) group of market participants. ${ }^{4}$ At times, prices convey information known to the seller but not to the buyer. At times, neither the buyer nor the seller is certain about the market clearing price. Among the possible reasons on the cost and demand sides, this section emphasizes rational reasons why buyers and sellers do not instantly know the permanence of changes in demand. They develop contracts and market arrangements to deal with this uncertainty.

This approach differs from the literature on so-called menu costs. The menu cost literature emphasizes costs of changing prices. ${ }^{5}$ These costs are recognized as relatively small (Ball and Mankiw, 1994). Moreover, the menu cost model does not explain why sellers face different costs and adjust at different speeds. I do not challenge the existence of menu costs, but the emphasis here is on uncertainty and information costs-the cost of learning about current and prospective market conditions. Information costs differ by firm and industry. They depend on the way in which markets are organized and the types of contracts that emerge to reduce costs of uncertainty, information and moral hazard.

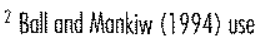

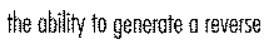
L-shope (Keynesion) sugply curve as evidence for a modet of ments costs ond imperfect competititon.

"This shoult not suggess that the firsigig is constent. As in Muth (1961), the timing of the sesponse depends on the relative varicnces of jermanent and tonsitory cornonents. See bellow.

"Whuch of this section is taken from Meltzer (1982), and especially Bunner and Maltzer (1993). Adectional exomples of rotional price setting when information is costly to ocesire con be found in these references. A recent poper by Henton and Luares (fortheonining) andigzes the effects of transection costs, suct as bid-rsk sprends, investor heterogeneity ond persis tence of shocks. They find thot mony puzztes in usset pricing con be reduced of removed by using models with tonstoctien costs and persistence. Braters and Cosimano (1990) model price odjustanent when firms must teom abous the persistence of changes in dermend.

${ }^{5}$ See Mcalum (1989) for a cilicol discussion of mente costs os a busis for rotiond priceteyel stickiness.
} 


\section{Morke Organizotion}

Frank Knight was an early expositor of the economics of information. Knight (1933), argued that decisions about how much and when to produce require a pooling of information about individual decisions to purchase. When aggregated, the individual decisions constitute a demand curve.

Firms reduce uncertainty for consumers by pooling information. In principle, individuals can contract in advance for the goods and services that they want. Organizing retail frms that pool information is an efficient alternative to futures contracts if individuals are less certain about the magnitude and timing of their purchases than firms are about market demand. Knight appeals to the law of large numbers to explain firms' advantage. He compares pooling by firms to insurance and concludes that the two differ in an important way; a firm's pricing and output decisions are non-insurable because they require more subjective judgment, and errors are less likely to cancel across firms.

In Knight's view, firms produce for inventory using pooled information about expected demand. This arrangement shifts uncertainty from individuals to firms and, by pooling, reduces the social cost of bearing uncertainty.

Knight's argument is one of several that links information costs and uncertainty to price setting. A non-uniform distribution of information is critical for these arguments. In an auction market, all market participants must have information about the qualities of the goods traded and their prices. In the standard Walrasian model, this is accomplished by: (1) assuming the presence of an auctioneer who calls out the prices;

(2) allowing recontracting; and (3) letting all trades be made simultaneously. These assumptions are necessary for equilibrium. They leave no role for monetary disturbances.

The necessary conditions are frequently violated in practice. Some people have a comparative advantage in acquiring information. Some receive information about market conditions as a by-product of other activity. For example, in securities markets, there are brokers, dealers and market makers who acquire specialized information in the course of trading. Assembling all or a sufficiently large number of market participants also imposes severe constraints. For many reasons, including the law of large numbers, people choose different times for their market activities. The commitment to assemble at pre-specified times for all marketing purposes is costly, if not impossible. The use of an agent introduces costs of monitoring and supervision.

In practice, markets operate in many different ways. One alternative commonly found in oriental countries is called a bazaar. Prices are not posted, and there is no auctioneer mechanism. Buyers and sellers negotiate (haggle) until a transaction is completed or the negotiation terminates. Considering a bazaar brings out the importance of information.

The bazaar requires an investment of time by transactors. Where the auction market requires simultaneous arrival of all participants or their agents, the bazaar depends on a trickle of arrivals. It cannot cope with large groups arriving simultaneously because each negotiation is separate. It is not surprising that the bazaar is found in comparatively simple, low-income economies. In these circumstances, the allocation of time to the bargaining process may be partly a consumption good. With rising opportunity costs of time, the disadvantages of the bargaining process exceed the benefits.

The working of a bazaar restricts its application. There are severe limits on the number of transactions per period. Sellers cannot serve several customers simultaneously. Delegating bargaining to employees poses both an incentive and a moral hazard problem. Buyers incur costs to learn about reservation prices, since information is revealed only by commitments to transact firm offers to buy or sell. An accepted offer to purchase may be above the seller's reservation price; a refusal to sell may be based on an incorrect inference that the buyer is willing to pay more. Learning the reservation price and negotiating the market price often requires a series of offers. There is no certainty that the reservation price is revealed. Subsequent transactors on one side of the market do not know the history of past transactions. They must invest their own time. 
relocate or search for a particular input at an inconvenient time.

\section{Lobor Morks}

The conditions leading to price setting also apply to the labor market. The terms negotiated and the time horizon built into an agreement depend on the assessments of the parties. There are no organized futures markets for labor. Both parties use all available information to form their uncertain assessments. An assessment of the tnarket is a (subjective) probability distribution. The more diffuse the distribution, the shorter the time covered by the arrangement.

Realizations often deviate from the expectations implied by the subjective probability distributions. Both parties have to infer from realizations whether the unexpected changes are transitory or permanent.

A transitory change does not change the expected value, so the unanticipated gains and losses do not change the information on which the agreement was based. Either party may believe that a costless revision of the bargain to adjust to a transitory change would be beneficial, but attempts at revision for each such change raise the cost of transacting and eliminate the benefits of a longer-term agreement.

A more permanent change in conditions poses a different problem. The initial assessment of at least one party must be revised in the light of the new information. If the stakes are sufficiently high, the permanent change may justify the cost of renegotiation.

Negotiations proceed more smoothly when both parties share the reassessment of market conditions. Differences in assessment provide evidence on the extent of uncertainty. Strikes and lockouts increase with differences in assessment, for example, at the start of a period of inflation or disinflation. If both parties could agree on the actual shocks that occurred in the past and on how long they will persist, they could contract in advance to compensate for unanticipated changes after they occur. Permanent changes in nominal values would not be allowed to affect real wages. Permanent changes in productivity would be paid to workers if positive and by workers if negative. That we do not observe contracts of this kind suggests that assessments differ even after the event and that reaching a common assessment of the past is costly. Of course, setting nominal wages is not costless either. Bargaining or negotiating to correct for unforeseen events can be costly, privately and socially, if there are strikes or layoffs. ${ }^{6}$

Differences in information can explain price setting, but they do not fully explain why firms and employees often set nominal wages or prices. There must be some additional cost of setting relative prices or benefit from setting nominal wages (or prices). One explanation is that the parties do not agree on the interpretation of real wages and, particularly at low rates of inflation, have difficulty agreeing on an appropriate index.

There are two different meanings of real wages. One meaning expresses real wages in terms of the product of the firm at which the worker is employed. The second refers to the basket of goods and services that the worker can purchase. The problems of setting contract terms differ in the two cases.

Contracts that set wages in relation to productivity require a satisfactory solution to the measurement of productivity. Where precise measurement is difficult, as in service industries or managerial tasks, real wage contracts are difficult to write. Even when productivity is measured reliably as in piece-work systems, the measure does not translate directly into a real wage rate. Valuation is required; often some (more or less) arbitrary system must be used to impute the price of the final product to the various inputs. Imputation and valuation bring two additional problems. One is moral hazard; the employer has some incentive to adopt a cost accounting system that benefits him. The other is the difference between relative and absolute prices. The employer is mainly concerned with the relation of wages to product prices. The employee is concerned also and perhaps most, about the relation of wages to the price of consumables - the second meaning of real wages. A frequent compromise in periods of inflation is partial indexation to the price of consumables.

Real wage setting with full indexation 
A seller who posts prices reduces the buyers' costs of acquiring information about prices. Buyers' costs of comparing prices by different sellers are reduced. The social advantage of price setting is greatest where one party to the transaction has more information about market conditions. Some examples illustrate this argument.

Information about prices conveys more than just purchase cost. Posted prices can also reduce costs of acquiring information about quality. For example, a restaurant owner must decide on the market he wants to serve. This decision influences the kind and quality of food served, the services offered, and the prices charged. By posting prices, the owner informs the buyer about his choices. Although the buyer must sample to judge quality, the correlation between quality and price helps the buyer to decide whether to sample. A policy of frequently changing prices reduces information and places the restaurant at a competitive disadvantage.

The organization of the diamond market provides additional evidence on the role of information in market organization. The wholesale diamond market is an auction. market dominated by buyers and sellers who are specialists. Traders rely on their own skill in judging quality, knowledge of prices and other atributes. The retail market is very different. The sellers are mainly specialists; the buyers typically have much less information than the sellers. By posting prices, sellers exploit the correlation between quality and price to inform buyers. Buyers find it less costly to invest in information about the seller than to invest in information about the quality of diamonds, so sellers use resources to build reputation. If costs of acquiring information about the quality of diamonds were to fall to a minimal value, these arrangements would change. Diamonds might be sold in supermarkets or in retail auction markets.

Price setting is valued by transactors even in some auction markets. In well-organized auction markets, we find people willing to pay for the right to purchase or sell at fixed nominal prices. The contracts expressing these rights, known as "put" and "call" options, give the owner the right to buy or sell at a fixed price within a fixed time period. The prices of the puts and calls are determined in auction markets. The price of these options is the cost that people pay for the right to trade in the future at prices fixed today. Similarly, in commodity markets, hedgers pay to change uncertain future prices into known values. They pay a fee for the right to buy or sell at fixed nominal prices. In such markets, information about current and currently anticipated future prices is available. The fee permits transactors to avoid uncertain future price changes.

Costs of information and transactions are not uniform across goods, so no single form of market organization dominates all others. The specific reasons transactors are willing to pay for puts and calls differ from the reason for price setting in the diamond market, just as the diamond market differs from the restaurant. Each is related, however. to costs of information. The organization of the diamond market reduces the costs of bearing uncertainty about quality. The market for puts and calls permits asset owners or speculators to limit risk of wealth changes. And there are other matket arrangements where price setting is useful. Catalogues must post prices. Contracts fix prices for a year or more on housing rentals, magazine subscriptions, and automobile leases. These many different examples suggest that there are advantages in different types of contracts.

The examples suggest a way to model price setung formally. The seller has information that is costly for the buyer to acquire. The seller internalizes the cost of acquiring the information; it is part of his specialized knowledge and he revises his information in the process of buying inputs. By posting a price, he exploits the correlation between price and quality. In goods markets, the seller may offer a particular type of put-an option for the buyer to return the merchandise if the quality is not as represented or, perhaps, if the buyer finds the same merchandise at a lower price. The buyer pays for the good and for the put, but the purchase cost is lower than under alternative forms of organization. In service markets, the buyer may purchase increased certainty that he will not have to 
is rare. This suggests that at low levels of inflation, buyers and sellers prefer ex post adjustment through negotiation to reliance on an imprecise or imperfect index. As inflation increases, costs of non-indexation rise relative to costs of indexation. More parties choose a mixed strategy of partial indexation. Experience in Israel and Brazil suggests that at relatively high rates of inflation, indexation is nearly, but never fully, complete. There is always some lag in adjustment. Data for countries with high inflation also suggest that workers willingly forego indexation if offered relatively stable prices.

The choice of an index is a problem for both parties. Some of the problem would be removed if shocks could be identified unambiguously, if one-time price changes (transitory changes in the rate of inflation) could be separated from permanent changes in inflation, or if all shocks were of one kind-for example, permanent, nominal or real aggregative, or real allocative. The absence of reliable information prevents settlement on an optimal indexation formula.

Nominal wage contracting is also not ideal. Different types of contracts are used to adjust nominal wages for inflation. In periods of low or moderate inflation, we observe contracts that differ in duration, in the extent of formal indexation, and in the use of clauses permitting reopening of the wage agreement during the life of the contract. We observe also that the types of contracts change with the rate of inflation and that employers can be induced to compensate for (some) past price changes when (non-indexed) contracts are renewed. At high rates of inflation, firms and other market participants monitor the rate of inflation. Costs that were previously marginal costs of information became fixed or quasi-fixed costs of information. Nominal prices adjust more frequently.

Retail store leases differ from wage contracts. Leases are often indexed to the volume of sales. Sales are more easily monitored and therefore less subject to moral hazard. Valuation is based on receipts, so measurement is not as much of a problem as for profits or productivity. Both parties have an interest in maintaining the property.

Bond contracts provide another example of the problem of choosing an index. Private parties do not issue price-level linked bonds. Under the gold standard, however, firms offered to pay in gold. Buyers and sellers could agree on this index of long-term value. Once this common measure, related to the value of money, became less relevant, indexed bonds were rare. Inability to agree on an index left no agreement. In Britain, Israel, Brazil and a few other countries, the government resolved this problem by issuing an indexed bond.

Comparison of the choices made in markets for labor, rental property and bonds suggests that agreement on an index is most difficult when prices can change because of real and nominal shocks, and changes can be permanent or transitory. This should not suggest that non-indexation is optimal. Contracting parties find many different solutions but, as experience in labor markets shows, full indexation is rare.

\section{A sylized Model}

In several papers, I have used a model of permanent and transitory changes based on Bomhoff (1983) to study the frequency of shocks and their interaction. A main conclusion of this work is that there is no reason to expect constancy or even repetition in the frequency distribution of shocks. The public cannot use data from the past to anticipate the future relative frequency of permanent and transitory shocks or real and nominal shocks. These frequencies change with public policy decisions, policy rules at home and abroad, weather, inventions or innovations, changes in market structure, and other factors affecting an economy's structural relations.

The model has three types of shocks: transitory shocks to the level; permanent shocks to the level (which are transitory shocks to the growth rate); and permanent shocks to the growth rate. Let $x_{t}$ be the current value of real output and $p$ the current value of the price level. Both prices and output can be affected by each of the three shocks so that

$$
\begin{aligned}
& \hat{x}_{t}=\bar{x}_{t}+\varepsilon_{t} \\
& \bar{x}_{t}=\bar{x}_{t-1}+\hat{x}_{t}+\gamma_{t} \\
& \hat{x}_{t}=\hat{x}_{t-1}+\rho_{t}
\end{aligned}
$$


and

$$
\begin{aligned}
& p_{t}=\bar{p}_{t}+u_{t} \\
& \bar{p}_{t}=\bar{p}_{t-1}+\hat{p}_{t}+v_{t} \\
& \hat{p}_{t}=\hat{p}_{t-1}+z_{t} .
\end{aligned}
$$

There are stochastic elements in the growth paths of output and inflation in addition to transitory and permanent changes in the levels of output and prices. Much confusion in the discussion of inflation has been caused by the use of "inflation" to refer both to level changes such as oil shocks (distributed over time) and persistent changes in the maintained rate of change.

Suppose we now introduce a common type of Phillips relation between $p$ and $x$ in the neighborhood of $p_{t}=1.0$.

$$
x_{t}-\hat{x}_{\xi}=\alpha\left(p_{t}-p_{t-1}\right) \text {. }
$$

The way in which prices will change over time depends on the permanence of the shocks. It takes time for agents to leam whether the shocks change $u_{t}, v_{t}$ or $z_{t}$ and, from the simultaneity of $x$ and $p$, shocks to $\varepsilon_{t}, \gamma_{t}$ and $\rho_{t}$. The path by which prices adjust-or the degree to which they are sticky - depends on the nature of the shocks. It is entirely rational in this framework for prices to be sticky and for the speed of adjustment to differ from one episode to another.

The model in Brunner, Cukierman and Meltzer (1983) conveys some of the ideas just discussed. The main idea of the model can be written in a general way. Consider the following system of simultaneous equations for a macroeconomic system. In the underlying micro model, firms set price at the start of the period and hold inventories. Shocks are revealed after production decisions are made.

$$
\left.f y_{t}, p_{i}, \Delta h_{t}, h_{t-1}, i_{t}, r_{t}, x_{t}, m_{t}\right\rfloor=0 \text {, }
$$

where $y=$ output, $p=$ price level, $h=$ stock of inventories, $i=$ nominal interest rate, $r=$ real interest rate, $x=$ exogenous real shock, and $m=$ nominal money stock. Under full information about the structure of the shocks and in the absence of transaction costs, the price level reflects current information about money. Money is neutral. Incomplete information of some sort is a necessary condition for significant monetary effects, but it is not sufficient.

Lucas' (1972) hypothesis about incomplete information restricts uncertainty to misperception of current shocks; people do not know whether a shock to demand is specific to their product or is a general increase in demand. It is now generally recognized that Lucas' hypothesis produces a response of real output to a nominal shock but does not generate as much persistence as is found in cyclical fluctuations of output and prices. Persistence must be introduced. The problem is to introduce persistence without introducing an implausible reason for neglecting information in current output, prices, interest rates and other variables.

In Brunner, Cukierman and Meltzer (1983), a representative producer sets price and output at the start of each period using all available information at the time. This includes, in particular, the variables in equation 1 -inventory levels and changes, interest rates and current policy. When making price and output decisions, producers are uncertain about the permanence of observed shocks. As in the earlier discussion, they do not respond to changes that are perceived to be transitory.

Let $x^{\star}$ and $m^{*}$ denote the perceived permanent components of $x$ and $m$. Knowing these values, producers set output and the price level; $y^{*}$ and $p^{*}$ denote the producers' decisions. They are determined from a subset of the system of simultaneots equations:

(2) $f\left[y_{t}^{*}, p_{t}^{*}, \Delta h_{t}^{*}, h_{t-1,} i_{t}^{*}, r_{t}^{*}, x_{t}^{*}, m_{t}^{*}\right]=0$.

The actual values are $x$ and $m$, but $x-x^{*}$ and $m-m^{*}$ are ignored in adjusting prices and output. Transitory changes are not innocuous. With $y^{*}$ and $p^{*}$ adjusted to $x^{*}$ and $m^{*}$, nominal and real interest rates and the change in inventories adjust to the perceived transitory changes, shown as equation 3 :

$$
f\left[y_{i}^{*}, p_{t}^{*}, \Delta h_{i}, h_{t-1}, i_{t}, r_{t}, x_{t}, m_{t}\right]=0 .
$$

Output, inventories and other real values 
respond to both nominal and real shocks in this model by amounts that depend on the size of the misperception. As new information arrives, producers revise their beliefs about the permanence of shocks; $p^{*}, y^{*}$ and all other variables adjust to the changed perception.

An econometrician examining the data generated by this model would at times find serially correlated changes in output and serially correlated errors. Serial correlation arises following a large permanent real or nominal shock if the shock is believed for a time to be transitory. As time passes, and errors are repeated, perceptions adjust. Even if the unconditional error in the population is serially uncorrelated, misperception of the permanence of shocks can lead producers to make errors that, ex post, are serially correlated. A model of this kind may explain why some researchers have found ex post real effects of anticipated changes in money. See, inter alios, Mishkin (1983).

Although prices do not fully adjust to shocks when they occur, decisions are entirely rational. Producers use all available information, but they misinterpret the nature of the shock. Once they perceive that the shock is permanent, prices and output fully reflect the information.

The length of the recognition lag depends on the relative variance of permanent and transitory shocks. The larger the variance of permanent shocks, relative to transitory shocks, the shorter the recognition lag. If all shocks were permanent, prices and output would adjust to $p^{*}$ and $y^{*}$ values as soon as the shocks occurred. The lag in our model would be one period, as in the Lucas model. If all shocks are transitory, $y$ and $p$ change, but $y^{*}$ and $p^{*}$ never adjust.

In Keynesian models, inflexible prices (or wages) and gradual adjustment are taken as evidence of disequilibrium. The information structure of the model here implies that this inference is invalid. Buyers and sellers use all available information and adjust to a market equilibrium.

There are three types of equilibrium. At any moment, there is a permanent stock equilibrium characterized by the state variables $x^{*}$ and $m^{*}$. This equilibrium occurs when $\Delta h=0$. The values of all variables are adjusted to the perceived permanent shocks and the condition of unchanging inventories. Each firm uses resources at the profit maximizing rate. No firm seeks to expand or contract output or change its price and inventory position.

A permanent equilibrium is less encompassing. The state variables in this case are $x^{*}, m^{*}$ and $h_{t-1}$. All other variables adjust to these conditions. If $x^{*}$ and $m^{*}$ remain unchanged, the permanent equilibrium converges over time to the permanent stock equilibrium.

A transitory equilibrium imposes an adjustment of the system to given values, $m \neq m^{*}, x \neq x^{*}, y^{*}, p^{*}$ and $h_{i-1}$. Inventory adjustment and interest rate changes produce the transitory short-run equilibrium.

In Brunner, Cukierman and Meltzer (1983) we show how real variables respond to monetary shocks in a model of this kind. All expectations are rational. No information is wasted once it is correctly perceived. Misperceptions occur, so the system adjusts sluggishly to information that, ex post, turns out to be permanent. The discussion here, following the original, uses inventories as a representative real variable but the response of real output is similar.

Figure 2 shows the adjustment path. Asterisks denotes permanent values, and a superscript $a$ denotes actual values.

"Up to period $t$, the economy is at an equilibrium: $H_{i}=H_{i}^{p}$. During period $t$, there is an unanticipated increase in money growth. Interest rates fall; with prices fixed for the period, aggregate demand increases, and inventories are reduced. Inability to identify permanent shocks means that the perceived value of $m$ changes as information about the rate of monetary expansion becomes available. Forecast errors remain on one side of zero for several periods. Forecast errors teinforce the cyclical deviation of inventories. A large permanent increase in money growth, that is not immediately recognized as permanent, increases $m_{t}$, and adds to the cyclical deviation of inventories. 


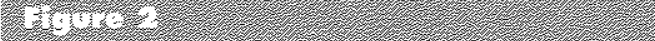

Inventory

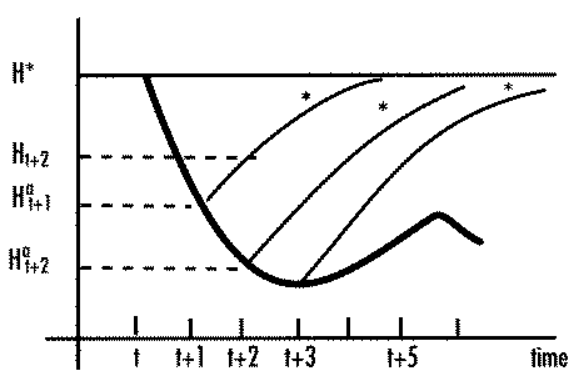

An asterisk in the ioble inditates the expected path of inventories. The outer envolope shows the atual poth.

"The reduction in inventories sets off a process of adjustment of output and inventories. The path along which inventories are expected to adjust at the onset of period $t+1$ is shown by the positively sloped line from $H_{i+1}^{a}$ to the permanent level of inventories, $H^{p}$. Along this path, a typical firm plans to produce output in excess of expected sales and build inventories. The expected value of inventories by the end of period $t+1$ is shown as $\mathrm{H}_{t+2}$. If the monetary shock is correctly perceived as transitory and there are no further shocks, firms adjust along the planned path and achieve the values of inventories, $\mathrm{H}_{t+2}$, $\mathrm{H}_{\mathrm{t}+3}$, in successive periods until the permanent value, $H^{p}$, is restored.

"Suppose, however, that the increase in money growth persists. In period $t+2$, interest rates are again pushed below the value expected for the period, and actual inventories, $H_{t+2}^{a}$, are, again, below the value expected, $\mathrm{H}_{t+2}$, as shown in fig. 2 . At the beginning of period $t+2$, firms and households expect the economy to adjust along the new path, from $\mathrm{H}_{t+2}^{a}$ to $H^{p}$. The new path reflects all the available information about the shocks, including beliefs about the permanence of the change in money growth and knowledge of the structural parameters...If the variance of the transitory component of money growth is large relative to the variance of the permanent component, adjustment to permanent changes is relatively slow. Inventories can fall below their expected value for several periods and, thus, move away from $H^{p}$.

"Additional information about the permanence of the shock that first occurred in period $t$ is revealed each period, so the path of adjustment toward $\mathrm{H}^{p}$ is not smooth. As time passes, however, the addition to information is small. After $1+3$ in fig. 2 , inventories adjust toward $H^{p}$ unless another shock-another unanticipated increase in money growth-lowers inventories and starts a new process of learning and adjusting.

"Actual inventories follow the outer envelope in fig. 2; expected inventories, $H$, follow the adjustment paths that start at the actual values for each period. The figure shows principal features of our model of inventory behavior, augmented by the effect of permanent-transitory confusion. Deviations from $H^{p}$ are on one side of $H^{p}$ for several periods because of the slow adjustment of inventories. This feature occurs even if all shocks are white noise. In addition, information about the permanence of shocks becomes available gradually. People use all information and their beliefs about permanent values to determine the adjustment path, but they make unavoidable errors because they learn about the permanence of shocks gradually."

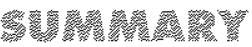

My emphasis in this section is on microfoundations that lead to price setting and to gradual adjustment. I do not claim to have uncovered a unique structure that produces sticky prices under rational behavior. There are many reasons and many valid. hypotheses that make both price setting and gradual price adjustment compatible with rational behavior.

Price setting is sufficient for real effects of monetary shocks. I have discussed several 
reasons for price setting-menu costs, Knight's uncertainty argument for the existence of firms, producers' desire to signal quality, purchasers' gains from lower cost of information and bargaining, and other differences in costs of acquiring information.

In principle, sellers or buyers could set relative, not absolute, prices. To do so efficiently, buyers and sellers have to agree on an index. Price index numbers are subject to real and nominal shocks that are sometimes permanent, sometimes transitory, and sometimes alter the rate of price change persistently. If these shocks could be correctly identified ex post, and if their expected duration were known, the parties might agree to adjust prices after shocks occur. Far more often, ex post adjustment is done by negotiation, or the parties agree to partial indexation and negotiate about the remainder. These arrangements are consistent with the presence of relatively large costs of acquiring information and agreeing on what has occurred, whether the change is permanent or transitory and how long and how large future price changes will be. Among these costs are the costs associated with moral hazard if one party controls relevant data.

Economic contractions typically last nine months to one year. Considerable evidence suggests that price changes may lag as much as two years behind monetary shocks. To yield the patterns of price and output change observed in actual economies, price setting must be joined to a rational reason for persistence.

Permanent-transitory confusion-uncertainty about the duration or persistence of shocks-provides one such condition. Under this hypothesis, lags can be long or short and ex post errors can be serially correlated, if a large permanent shock is perceived as transitory. If the variance of $t$ he permanent shocks is high relative to the variance of transitory shocks, the lag is relatively short, and there is no reason for significant serial correlation to be observed ex post. In this case, price setters believe that most shocks are permanent, so they adjust promptly.

\begin{tabular}{|c|c|c|}
\hline \multicolumn{3}{|c|}{$\begin{array}{l}\text { Revisions to Reported Inflation } \\
\text { (percentuge points) }\end{array}$} \\
\hline $\begin{array}{l}\text { Horizon } \\
\text { (quarters following) }\end{array}$ & $\begin{array}{l}\text { Average } \\
\text { Revision }\end{array}$ & Range \\
\hline 1 & 0.2 & -1.0 to 1.5 \\
\hline 2 & 0.3 & 1.2 to 1.7 \\
\hline 3 & 0.3 & 0.6101 .7 \\
\hline 4 & 0.3 & 0.6101 .7 \\
\hline
\end{tabular}

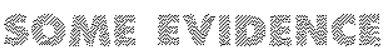

We cannot directly observe how people decide on the degree of persistence in the rate of inflation (or other variables). However, we can measure some of the errors that contribute to permanent-transitory confusion and use econometric methods to estimate the variance of permanent and transitory errors in the price level (or other variables). This section considers these sources of evidence on the relative size of permanent and transitory changes.

Bullard (1994) reported the size of revisions to quarterly reports of the rate of change of the GNP deflator for the years 1986 through 1992. He found that the mean revision for the 28 quarters was positive in this period; early reports understated the rate of inflation and later revisions added additional amounts. Bullard also reports the range of revisions for each of the four quarters following the period considered. The reported ranges exclude the most extreme 5 percent of the revisions in each tail. Table I reproduces Bullard's results.

The average rate of inllation for the period is approximately 3 percent. The range of revisions (excluding extreme values) is 2.3 to 2.9 percentage points. The revisions are from 70 percent to 130 percent of the ( 3 percent) average reported change. The relatively large size of the revisions suggests that it is rational for the public to act as if the initial announcement is a very noisy indicator of the true rate of inflation.

In several papers summarized in Brunner and Meltzer (1993), we report forecast errors for the rate of change of output or inflation using different models, methods of forecast and countries. The forecasting 
methods include state-of-the-art econometric modeling, time-series analysis, judgment and combinations of these methods. A

rule-of-thumb summary is that mean absolute errors for output growth in the major industrial countries is 50 percent or more of the average rate of change one quarter or one year ahead. Inflation is less variable than output over short periods, and its forecast error is a smaller fraction of the average rate of change. Still, errors in both. growth and inflation forecasts are large.

The data on forecast errors make a persuasive case that forecasters frequently misperceive future values. Data on revisions suggest that current reports are subject to large errors. Errors may be unbiased, but that is a small consolation for those who adjust to events that are found later not to have occurred or those who do not adjust to changes that did occur. The permanent-transitory distinction implies that partial adjustment is optimal. Ex post, it will seem that adjustment has been sluggish. Indeed, as noted, errors may appear to be serially correlated following large changes.

A filter can be used to separate permanent and transitory components. ${ }^{7}$ Let the error term in an aggregate such as the price level or output have a permanent and transitory component,

$$
\varepsilon_{\mathrm{t}}=\mathcal{E}^{p_{1}}+\mathcal{E}^{\tau_{1}}
$$

where $p$ and $\tau$ denote the two components. The transitory component is white noise. The permanent component has the property of zero mean and constant variance, $\sigma^{2}$.

$$
\Delta \varepsilon^{p}-N\left(0, \sigma_{p}^{2}\right)
$$

At any time t, the expected change in the permanent component is zero.

People observe prices and output. As in

TSee Bombof ( 1983 ) for a discussion of the Boyesian mitti-state Kaman filter

${ }^{8} \mathrm{~A}$ is the odjustenent log given by $\lambda=\sqrt[a+\frac{a^{2}}{4}-\frac{a}{2}]{a}$

and $a$ is the ratio of the woriche of the permetritent component to the velibere of the fronsitory component. the quicker the economy adjusts to permanent changes. A relatively large transitory variance slows the response.

Meltzer (1986) estimated the variances of the permanent and transitory components of inflation and growth for Canada, Germany, the United Kingdom, and the United States under fixed and fluctuating exchange rates. The fixed exchange rate period runs from the first quarter of 1960 through the third quarter of 1971 . Fluctuating rates begin in the fourth quarter of 1971 and end in the fourth quarter of 1984 . $^{\circ}$

Table 2 shows the ratios computed from these data using the adjustment equations in Muth (1960). The estimated variance ratios for inllation and growth changed under fluctuating rates, but the direction of change is not uniform across countries. The length of the adjustment lag required to distinguish permanent from transitory shocks changed much less. For inllation, seven of the eight values of the adjustment lag $(\lambda)$ lie between 0.41 and 0.56 . These values imply that, consistent with Blinder's survey data, about half of the shock to inflation is seen in the current quarter. Between 82 percent and 96 percent of the adjustment of permanent inflation occurs within four quarters of the initial shock to the inflation rate. This adjustment is faster than the two-year average lag commonly suggested. For real growth, seven of the eight values of $\lambda$ lie between 0.45 and 0.67 ; within four quarters, 91 percent to 99 percent of the adjustment occurs. The speed of output adjustment is broadly consistent with the length of post-war recessions if these recessions are interpreted as the cumulative adjustment set off by a monetary or real shock. Inflation adjusts more slowly than growth as many studies have shown.

Clarida and Gali (1994) studied the response of real exchange rates to nominal shocks in four countries. For Canada and the United Kingdom, they were unable to find any structural effects-real or nominal-on real exchange rates.

For Germany and Japan, the evidence suggests that nominal shocks explain 45 percent and 34 percent, respectively, of the four-quarter-ahead forecast error variances of the log level of bilateral real dollar exchange 
rates. Clarida and Gali note that their estimates are consistent with the evidence from vector autoregressions reported in Eichenbaum and Evans (1992).

Clarida and Gali (1994) use a trivariate vector autoregression to estimate the transitory component of real exchange rates. ${ }^{\text {. }}$ Their model includes shocks to aggregate demand and supply. The authors report the ratio of the variance of transitory shocks to the variance of actual shocks. Using their data, we can compute the ratio of the variance of permanent shocks to the variance of transitory shocks. The ratio covers a wide range in these countries-from 0.42 in Germany to 3.76 in Canada. These findings suggest that most shocks to the Canadian real exchange rate have been permanent while most shocks to the German real exchange rate were transitory Hence, the Canadian real exchange rate should adjust more rapidly to shocks than the German real rate.

Meltzer (1993) used the permanenttransitory distinction to model the U.S. multilateral real exchange rate. For both levels and first differences under fixed and fluctuating rates from 1960 to 1991, the data suggest that there is a large permanent component in the change of the real exchange rate and a significant transitory component. Further, the data suggest that the multilateral real exchange rate responds to changes in the nominal stock of money. The effect eventually vanishes, but monetary changes have real effects until prices adjust. These findings are consistent with short-run non-neutrality and long-run neutrality of money if permanent changes in money were perceived as transitory at the time they occurred or conversely.

The studies of prices, output and exchange rates support the principal arguments of the article. They are only a small part of the evidence supporting ex post, short-run non-neatrality. They are of interest because they attribute slow adjustment of nominal values and real effects of nominal shocks to the difficulty of disceming the persistence of shocks. With a non-trivial cost of acquiring information, price setting and permanent-transitory confusion imply that nominal changes have real effects that persist for a time.

\section{(1)}

Relative Variances of the Permanent and Transitory Components

1960-71

\begin{tabular}{|c|c|c|c|c|}
\hline & Cannda & Germany & U.K. & U.S. \\
\hline Inllation & 0229 & 156 & 0.37 & 0.71 \\
\hline$\lambda$ & 0.41 & 0.69 & 0.45 & 0.56 \\
\hline Eeel growtl & 0.62 & 0.65 & 036 & 111 \\
\hline \multirow[t]{3}{*}{27} & 0.57 & 0.54 & 0.45 & 0.64 \\
\hline & \multicolumn{4}{|c|}{$1971-84$} \\
\hline & Canada & Germany & U.K & U.S. \\
\hline Inflaition & 056 & 0.30 & 0.31 & 0.71 \\
\hline p & 0.52 & 0.42 & $0: 42$ & 0.56 \\
\hline Reel growth & 135 & 1.00 & 0.04 & 0.86 \\
\hline$\lambda y$ & 0.67 & 0.62 & 0.18 & 0.59 \\
\hline
\end{tabular}

Other recent studies find evidence of costs of acquiring information.

Investors frequently pay a premium to buy country-specific mutual funds. The premium implies that they could buy the individual securities at lower cost. If they are uncertain about which securities to buy and when to buy or sell, it may be rational to pay for the services of traders who specialize in the particular market.

Smith (1991) uses costs of acquiring information as one reason for the absence of oprimal portfolio diversification of world market securities. The degree of diversification depends on costs of acquiring information. People know much more about values and earnings in their own market that in foreign markets. Prices in foreign markets may reflect full information, but some investors either do not have this information or cannot assess whether changes are permanent. Hence, they do not respond promptly to information about each of these markets. They do not hold the "true" equilibrium portfolio they would hold if information costs were zero. A principal cost in this case, as in others, is the interpretation of avallable information. Pemanent-transitory confusion is one part of the interpretation problem.

In Fuhrer and Moore (1993), the inflation
"The tiveriote system has four logged walles of the change in ing log rent exdhenge rote, the chonge in the log ratio of torited States hore coutrin real GDP, and the difference between U.S. ond for eign inftation. Datuo are quarterly from rnid 1970 to the fourtith quanter of 1992 . 
rate is sticky. Firms adjust relative prices to the average of other sectors' expected relative prices over the life of existing contracts. Firms also adjust for the current and expected level of output. The autocorrelation functions based on their model have very similar shapes to the autocorrelations generated by an unconstrained vector autoregression. In particular, they show considerable persistence in inflation and output movements and sustained effects of inflation on real output. In short, Fuhrer and Moore provide evidence that is consistent with a model in which there are costs of learning about the permanence or persistence of changes, and in which people adopt strategies that leave room for misperception and real effects of nominal changes.

Earlier work by Boschen and Grossman (1982), Gordon (1982) and Mishkin (1983) also provide evidence that supports sticky prices. Indeed, the evidence of gradual adjustment of prices and of short-term real effects of monetary change is common. These studies lack micro-foundations. Price-setting in part of the economy and permanent-transitory confusion, as in Brunner, Cukierman and Meltzer (1983), reconciles this evidence with rational behavior.

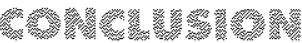

The examples in the preceding section are a small part of the recently accumulated evidence showing that there is much more than casual observation to support the main propositions in this paper: Nominal prices adjust with a lag. The lag is sufficiently long that real variables respond to nominal changes. Costs of acquiring information about the persistence of observed changespermanent-transitory confusion-is a main component of the cost and a main reason for the lag. Even where prices reflect information fully, all individuals or firms may not have adjusted fully to available but costly information.

The oft-repeated comment that macroeconomics should be built on micro-foundations is correct if and only if the micro-foundations are appropriate for the task. Standard micro theory, such as Arrow-Debreu, imposes complete markets and market clearing in each market. There is no role for monetary disturbances. This is not the appropriate micro-foundation for macroeconomics. No amount of squeezing, cutting and pasting will make it so.

Rational behavior and rational expectations are entirely consistent with costs of acquiring information and the inability to fully identify permanent and transitory shocks either when they occur or for several quarters after. Indeed, Muth's (1961) initial formulation of rational expectations is based on the latter distinction.

One alternative explanation of sticky prices in recent literature relies on menu costs and imperfect competition. This explanation is a foundation for the so-called L-shaped supply curve familiar from Keynesian theories. I show that the evidence in Blinder's (1991) survey rejects the L-shaped supply curve. Further, the implications of monopolistic competition, such as widespread excess capacity, do not explain gradual price adjustment in most service industries.

Gordon (1990) proposes a disaggregated system to take account of the information at many levels of the economy. He argues that prices respond to marginal cost but that marginal cost for any firm depends on the pricing strategy of its suppliers. Hence, such infor mation enters firms' decisions about price and output adjustment. Information from macrodata is much less relevant.

This argument captures some of the dynamics of pricing, but it poses unresolved challenges for aggregation over different. industry structures. Moreover, Gordon's framework implies that commodity producers should adjust slowly to aggregate shocks and that large firms in durable goods industries should adjust promptly. The stylized facts suggest that the opposite is true. One reason is that organized commodity markets increase the information available to commodity producers. There are no comparable markets for consumers' and producers' durable goods output. Differences in information and the costs of acquiting information are consistent with the stylized facts on speed of adjustment. qunter of 1992 . 
The micro-foundations suggested in this article use costs of acquiring information to explain three common observations. First, many prices are set. Second, price setters choose nominal values. Third, the daily, weekly, monthly or quarterly variances of "set prices" are small fractions of the variance of prices in auction markets; set prices are stickier.

Households and firms do not operate in a world of full information. Incomplete information and costs of acquiring information are central problems of a monetary economy. Information and transaction costs explain why people hold and use money as a medium of exchange (Brunner and Meltzer, 1971). There is considerable evidence that these costs are not trivial. The article cites revistons to reported data, forecast errors, incomplete information about costs, profits and strategies of competing firms. These examples do not exhaust the costs that firms and individuals face.

Some of these costs can be reduced by institutional and contractual arrangements. The arrangements that people choose may be optimal when contracts are written but, with changes in the environment, there are unforeseen gains and losses. If the gains and losses are transitory, their expected value is zero. It may not be worthwhile to change the contract or the method of contracting. Once the change is considered persistemt, gains and losses are expected to cumulate. Adjustment of re-negotiation becomes more appealing to at least one party.

Information about permanent and transitory changes in profits, prices, wages and other variables is costly to acquire. The distribution of shocks between real and nominal, permanent and transitory may differ from one sample period to the next. People learn to monitor events or changes that are costly to ignore. But learning requires a continuous process of monitoring both what has happened and what should be observed. This is a basic problem for firms and households. As such, it is a more appropriate micro-foundation for macroeconomics.

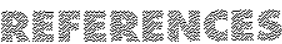

Achion, Armen A. "Why Money?" Journd of Money, Credt and Banking (Februan 1977, pert 2), np. 1334-40.
Ball, Laurence, and N. Gregory Mankiw. "A Sticky Price Manifesto," Connegie Rochester Conference Series on Public Policy (December 19941, pp. 127-52.

Balvers, R. J., and T. F. Cosimona. "Actively Leaning About Demand ond the Olynanics of Price Adjustment," Economic loumol (Sentember 1990) pp. $882-98$

Baumel, Willion I. "The Transactions lemand tor Cash: An Inventory Theorefic Approuch," Quorterly Jound of Economics (Novenber 1952), po. 545.56 .

Bequlieu, los., and toe Mottey. "The Effects of General Intlation and Idiosynantic Cost Shacks on Within-Commodity Pice Dispersion: Evidence from Microdata," Finance and Fronomic Discussion Series No. 94-12 (May 1994), Bont of Govenners of the Federd Reserve System.

Blinder, Alan S. "Why Are Prices Sticky? Preliminory Results from on "nferview Study" The Americon Economic Review (Moy 1991), pp. 89-96.

Bemhoff, Eduard J. Monetory Lncertainty. Nooth Holland, 1983.

Boschen, Jahn F., and Herschel I. Grossman. "Tests of Equilibstum Mocroecononics Using Contemparoneous Monetory Doto," Journd of Monetory Econonics (Novembet 1982), pp. 309-33.

Bumer, Korl, and Allon H. Metzer. Money and the Econony. Issues in Monetary Anolysis. Conbridge University Press, for the Roffaele Mottioli lectures, 1993.

and __. "The Uses of Money: Money in the Theory of an Exciange Economy," The Americon Exonomic Review (December 1971), pp. 784.805. and __ "Economies of Scole in Cash Balones Reconsidered," Quorterly Jound of Ecomomics (August 1967), pp. 422-36.

Alex Cukieman ond Allon H. Meltzer. "Honey and Economic Activity: Inventories and Business Cycles," Jound of Monetory Economics (Moy 1983), pp. 281-319.

Buliond, James B. "How Reliable Are Inftotion Reports?" Federd Reserve Bank of St. Louis Monetory Trends (Februan 1994), p. 1.

Corida, Richand, and Jord Gati. "Seurces of Real Exchange Rote Fuctuations; How mpotunt Are kaminal Shacks?" Conngie Rochester Conference Series on Public Policy (lecember 1994), pp. $\ 56$.

Eichenboum, Martin, ond Choles Evons. "Some Empiricol Evidence on the Effects of Honefary Policy Shocks on Exchonge Rates," Federal Reserve Bank of Chicago Working Poper No. $92-32$ (December 1992).

Futrer, Seffrey, and George Moore. "Inflation Persistence," Finonce and Economic Discussion Series No. 93-17 (Moy 1993), Boord of Govennors of the Federal Reserve System.

Gerdan, Robert!. "What Is New-Keynesion Economics?" Jounnol of Economic literoture (September 1990), pp. 111571.

"Price Inertia and Policy Ineffectiveness in the United States, 1890-1980," Jound a Political Economy (December 1982), pp. 1087-1117. 
Heoton, John, and Debro Lucos. "The Importance of Inyestor Heterogeneity and Finoncint Market Imperfections for the Behovior of Asset Prices," Contegie Rochester Conference Series on Public Policy (forthooning).

Knight, Fronk H. Risk, Uncertointy ond Profit (Wo. 16 in repints of Scare Classics in Economics). Lonton School of Economies, 1933.

Lucas, Robert $\mathrm{E}$, Je. "Expectrations ond the Neutrdity of Money" Jound of Economic Theory (April 1972), pp. 103-24

Mocallum, Bennett T. "New Conssicol Macroeconomics: A Sympotheicic Account," Scandinowion Jound of Econornics (June 1989). pp. 223-52.

Meltzer, Alan H. "Real Exchonge Rates: Some Evidence from the Posswar Yeas, this Review (Mard/Aprit 1993), ap. 103-17.

"Size, Persistence ond the Interrelation of Narrinatal and Real Shoks; Some Evidence from Four Countries," Jound of Monetary Economics (Januany 1986), pp. 161-94.

"Rotiond Expectations, Risk, Uncertainty ond Market Responses," in Poul Wathtel, ed., Gises in the Economic and Financial Stwuture. Lexington Books, 1982, pp. 322 .

Mishkin, Fredrick S. A Rotiond Expectations Approoch to Mocroeconometrics: Testing Policy lneffectiveness ond Efficient Markefs Models. University of Chicago Press, 1983.
Muth, John F. "Rationat Expectotions and the Theory of Pice Moverments," Econometrica (Juty 1961), pp. 315.35.

"Optimat Properties of Exponentially Weighted Forecosts," Jound of the Americon Statisticol Associotion (June 1960), pp. 299.306.

Smith, Clifford W. J. "Globalizotian of Financis Mokets, "Connegie Rochester Conference Serias on Public Policy (saing 1991), Ap. $77-96$. 